\title{
Evaluation of green building incremental cost and benefit based on SD model
}

\author{
Guoqiong Long ${ }^{1, *}$, Tianxiang $\mathrm{Xu}^{2}$, and Chong $\mathrm{Li}^{1}$ \\ ${ }^{1}$ School of Economics, Yunnan University of Finance and Economics,650221 Kunming, China \\ ${ }^{2}$ Economics Development Research Center of Yunnan University of Finance and Economics,650221 Kunming, China
}

\begin{abstract}
In order to eliminate the characteristics of long payback period and external economy of green building investment, and realize the accurate evaluation of green building cost and benefit. Based on the new estimation method, this paper constructs the system dynamics(SD) model of incremental cost-effectiveness of green building, and the rationality of the model is further tested and judged. This paper studies the change law of incremental cost and benefit of green building energy saving from the perspective of SD model. The incremental benefit of green building is greater than the incremental cost, and the time balance between them is about 8.0 years. The conclusion can provide enlightenment for the further development of green building.
\end{abstract}

\section{Introduction}

Under the pressure of the decline of environmental quality and the sharp increase of energy consumption, in order to change the current situation of the construction industry, it has become a consensus to establish sustainable green building. Therefore, green building has been rapidly promoted. However, due to the use of energy-saving technology, intelligent system, recycling and other technical facilities, the construction cost of green buildings is much higher than that of ordinary buildings, and the direct and indirect benefits generated in the use process are also higher than ordinary buildings. Therefore, it is particularly important to study the incremental costeffectiveness of green buildings. At the same time, the current theory and understanding of green building is not mature enough, and the knowledge of incremental cost and benefit of green building is still vague. Most of the evaluation of green buildings is from the perspective of technology and economy. There is no systematic evaluation system of comprehensive benefits of green buildings, and the evaluation of comprehensive benefits also has different degrees of deviation[1]. In view of this, it is necessary to scientifically evaluate the cost-benefit level of green building and study the comprehensive benefit of green building on the basis of current domestic and international research on the cost-effectiveness of green building.

In addition, the government, property developers and consumers are the participants of green building construction in China. Among them, the government plays a leading and promoting role. As the executive body, developers will be restricted by the problem of high incremental cost. Although consumers can obtain incremental benefits by purchasing green buildings, they should also share the incremental costs transferred from developers[2]. Therefore, in the construction design of green building, it is necessary to construct the cost control model of green building. Combining with cost control and the estimation method of system dynamics parameters, the cost prediction and engineering cost control of green building are carried out. It has important practical significance to improve the quality of green building construction and reduce the cost of green building[3]. This paper studies the incremental costs and benefits of green buildings and ordinary buildings by using the method of "with or without comparison". Based on the theory of system dynamics, the constrained parameter model of building cost-benefit evaluation is constructed, which can accurately estimate the cost-benefit results and draw effective conclusions.

\section{Incremental cost and benefit analysis of green building}

Cost benefit evaluation of green building is a comprehensive evaluation including incremental benefits of economy, environment and society, and incremental costs of management and maintenance. This requires a systematic induction of different types of cost-benefit elements. See Figure 1 for details.

\subsection{Evaluation index of incremental cost}

The incremental cost of green building refers to the incremental investment brought by adopting green building technology different from the benchmark building in order to realize the Green function of buildings[4]. It mainly includes two aspects: The first is the purchase cost, which mainly includes the design cost and material cost of the developer. The developers transfer

* Corresponding author: lichong@ynufe.cn 
the increased green building construction cost to consumers, mainly by increasing the sales price to make consumers bear the purchase cost. The second is the operation and maintenance cost, mainly including the incremental cost of the installation, management, repair, replacement and so on of the energy-saving facilities in the use process. Operation and maintenance is the main stage to generate incremental costs and benefits. Due to the adoption of some green technologies and facilities, the operating costs increase. Through the comparative analysis of energy-saving technologies in more than 20 green building projects, and combining with the relevant evaluation indexes of "energy conservation and energy utilization" in GB/T50378-2014, the following indicators are finally screened out. See Table 1 for details.

Table1. Incremental cost index system

\begin{tabular}{|c|c|}
\hline Primary indicators & Secondary indicators \\
\hline \multirow{3}{*}{ Energy saving and energy utilization } & $\begin{array}{l}\text { Energy saving maintenance structure (Energy saving roof, energy saving doors and windows and building floor } \\
\text { cost) }\end{array}$ \\
\hline & Energy saving lighting system (Cost difference between natural lighting and green lighting) \\
\hline & Renewable resource systems (Cost of solar energy, geothermal energy and wind energy) \\
\hline \multirow{3}{*}{ Land saving and outdoor environment } & Site utilization (Increased cost of abandoned sites and underground space) \\
\hline & Outdoor environment (Cost of noise control, ground landscape design, three-dimensional greening) \\
\hline & Pervious ground (Cost increase caused by permeable paving method and permeable floor tile) \\
\hline \multirow{3}{*}{$\begin{array}{l}\text { Water saving and utilization of water } \\
\text { resources }\end{array}$} & Water saving system (Water source collection, reasonable discharge, etc.) \\
\hline & $\begin{array}{l}\text { Water saving equipment (Cost difference of water-saving faucet and water-saving sanitary ware compared with } \\
\text { ordinary equipment) }\end{array}$ \\
\hline & Water recycling (Increased cost of clear roads, toilet cleaning, air conditioning cooling water) \\
\hline \multirow{3}{*}{ Material saving and material utilization } & $\begin{array}{l}\text { Green building materials (Increased cost of construction materials with little environmental impact and no } \\
\text { pollution) }\end{array}$ \\
\hline & Material recycling (Cost increase to improve the utilization of building materials) \\
\hline & Waste recycling (Increased cost of waste treatment) \\
\hline
\end{tabular}

\subsection{Evaluation index of incremental income}

The incremental benefits of green buildings are mainly reflected in three aspects: economic benefits, social benefits and environmental benefits. As the direct benefit of green building, economic benefit is reflected in water saving, energy saving, government subsidies and so on. The cost-effectiveness of using process is usually due to the use of various green building equipment during the construction period, such as energy saving, water saving, material saving and other cost saving, which are manifested in the improvement of economic benefits. The benefits of government subsidies can be realized in the form of deed tax return or other forms. Environmental benefits mainly refer to the benefits from the use of green building materials and the implementation of environmental protection measures in the whole construction process, which can reduce pollution, prolong the life of buildings and reduce the occurrence of diseases. The social incremental benefits of green buildings are due to the use of green building materials and the implementation of environmental protection measures in the whole process of construction. Consumers can reduce diseases caused by living environment, reduce medical expenses, ensure physical and mental health, improve work efficiency, and increase welfare and income.

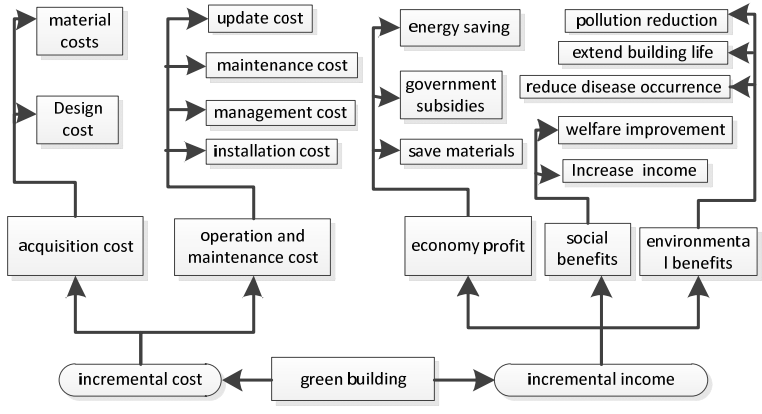

Fig1. Components of incremental costs and benefits

\section{Construction of SD model for incremental cost and benefit of green building}

System dynamics method is an important part of system engineering theory, which can reflect the whole process and simulate[5]. Therefore, the system dynamics method can be used to simulate the incremental cost-benefit analysis of green building in this paper, and has good applicability.

\subsection{System objectives}

Based on the dynamic theory, the incremental cost-benefit evaluation model of green building is constructed, which 
considers the influence of consumers, government and developers on the research object. Green building provides a more reasonable and healthy green working environment, so consumers should pay extra for it. At the same time, in order to promote the popularization of energy-saving technology in green building industry, the government not only introduced relevant subsidy policies, but also formulated mandatory laws and regulations to promote the orderly development of green building market. Whether green building developers use energy-saving technology depends on the cost-benefit ratio of incremental cost and benefit and the payback period of investment. Therefore, the model should not only consider the relationship between green building operation cost reduction and energy-saving technology utilization, but also pay attention to the environmental and social benefits contribution.

\subsection{System boundary}

According to the theory of system dynamics, the interaction between the internal elements of the system is the fundamental driving force to promote the dynamic behavior of the whole system. Under the influence of external environment, the whole system is easily affected, so it shows certain complexity and dynamics. In order to ensure the accuracy of the model calculation results, the boundary of the incremental cost-benefit index system of green building should be defined to reduce the complexity of the system as much as possible. Therefore, the incremental cost-benefit system is divided into incremental cost subsystem and incremental benefit subsystem. By determining whether the incremental costs and benefits have a greater impact on the objectives under study, the larger and more significant incremental costs and benefits are included within the system boundary, while some less significant incremental costs and benefits are ignored and divided outside the system boundary. When determining the boundary of incremental income index system of green building, the most basic unit of incremental benefit subsystem of green building is formed by referring to the construction form of incremental cost index in Table 1.

Table2. Incremental income index system

\begin{tabular}{|c|c|}
\hline Primary indicators & Secondary indicators \\
\hline \multirow{3}{*}{ Energy saving benefit and lighting } & $\begin{array}{l}\text { Heating air conditioning (Energy consumption difference of heating and air conditioning in green buildings } \\
\text { compared with traditional buildings) }\end{array}$ \\
\hline & $\begin{array}{l}\text { Energy saving lighting system (Energy saving difference between energy saving lighting system and ordinary } \\
\text { lighting system) }\end{array}$ \\
\hline & Renewable resources (Electricity saved by using renewable resources in green buildings) \\
\hline \multirow{3}{*}{$\begin{array}{l}\text { Land saving and outdoor } \\
\text { environment }\end{array}$} & Land purchase (Saving land resources and purchase cost by using waste sites) \\
\hline & Welfare benefits (Benefits from noise control, ground landscape design and three-dimensional greening) \\
\hline & Underground space(Relieve the pressure of land use and improve the land utilization rate) \\
\hline \multirow{3}{*}{$\begin{array}{l}\text { Water saving and utilization of water } \\
\text { resources }\end{array}$} & Comprehensive utilization of rainwater (Water saving) \\
\hline & Comprehensive utilization of reclaimed water (Reclaimed water recycling capacity) \\
\hline & Water saving facilities (Amount of rainwater recycling) \\
\hline \multirow{3}{*}{$\begin{array}{l}\text { Material saving and material } \\
\text { utilization }\end{array}$} & Green building materials (Building material savings) \\
\hline & Material recycling (Structural material savings) \\
\hline & Waste recycling (Material cost savings) \\
\hline
\end{tabular}

\subsection{Model construction and verification}

\subsubsection{Feedback loop.}

This paper qualitatively studies the feedback process and relationship among the components within the system boundary by drawing the causality diagram, which is the basis of constructing the incremental cost-benefit evaluation model of green building. The specific drawing process is as follows: firstly, combining with the relationship between incremental cost and incremental benefit defined by the previous system, the causal relationship of incremental benefit system is drawn. Secondly, the causality analysis of incremental benefit system shows that the energy consumption level of green building is reduced due to the adoption of energy-saving technology, which reduces the emission of polluting gas, and correspondingly reduces the medical cost of residents, which can strengthen the willingness of residents to purchase the green building and improve the income of developers. Thirdly, the causal relationship between incremental benefits and incremental costs is analyzed. Developers can not only obtain direct benefits such as government subsidies and energy-saving economic benefits, but also obtain indirect benefits such as the increase of house price income and the extension of building life. By drawing the causal relationship and combing the relationship between the elements in the incremental cost-benefit system of green building, three feedback loops are obtained, all of which are positive feedback loops. The circuits are as follows:

Loop 1: Incremental cost $\rightarrow+$ Energy saving technology level $\rightarrow+$ Reducing emissions of polluting gases $\rightarrow+$ Medical cost reduction $\rightarrow+$ Willingness intensity $\rightarrow+$ Incremental income $\rightarrow+$ Incremental cost.

Loop 2: Incremental cost $\rightarrow+$ Energy saving technology level $\rightarrow+$ Building life extension $\rightarrow+$ 
Efficiency improvement $\rightarrow+$ Income increase $\rightarrow+$ Willingness intensity $\rightarrow+$ Housing purchase rate $\rightarrow+$ House price income $\rightarrow+$ Incremental income $\rightarrow+$ Incremental cost.

Loop 3: Incremental cost $\rightarrow+$ Investment rate of energy saving technology $\rightarrow+$ Government subsidy $\rightarrow+$ Willingness intensity $\rightarrow+$ House price income $\rightarrow+$ Incremental income $\rightarrow+$ Incremental cost.

\subsubsection{Drawing of stocks and flows change chart.}

Compared with the incremental cost-benefit causality of green building, the stocks and flows chart is adjusted according to the system dynamics equation. The specific drawing process is as follows: Firstly, considering the availability of data and the operability of the model, the constant of usage, maintenance, operation, management and update incremental cost is added to the inventory flows chart. Secondly, four state variables of economy, society, environment and incremental benefit are introduced into the stocks and flows chart.

\subsubsection{Construction of system dynamics equation.}

The system dynamic equation between variables is established by dynamo language in software Vensim combined with stocks and flows chart. After the variables and parameters of the model are determined, the variable equation of the model should be edited. There are many variables and equations involved in this model. The details are as follows:

Final time $=25$, units: year, initial time $=0$, units: year.

(1) Incremental cost $\left(\mathrm{L}_{1}\right)=$ (maintenance incremental cost $\mathrm{L}_{3}+$ operation incremental cost $\mathrm{L}_{4}+$ management incremental cost $\mathrm{L}_{5}+$ update incremental $\left.\operatorname{cost} \mathrm{L}_{6}\right) \times$ pulse $(0,4)$, units: $\mathrm{RMB} / \mathrm{m}^{2}$; (2) Incremental maintenance cost $\left(\mathrm{L}_{3}\right)=($ maintenance charge standard $\times$ actual charge area $)$ $\times$ pulse $(0,2)$, units: yuan $/ \mathrm{m}^{2}$; (3) Operating incremental cost $\left(\mathrm{L}_{4}\right)=$ (energy saving product consumption reduction rate $\times$ operation charging standard) $\times$ pulse $(0,2)$, units: yuan $/ \mathrm{m}^{2}$;(4) Management incremental cost $\left(\mathrm{L}_{5}\right)=$ (energy saving product consumption reduction rate $\times$ management cost standard) $\times$ pulse $(0,2)$, units: yuan $/ \mathrm{m}^{2} ;(5)$ Update incremental cost $\left(\mathrm{L}_{6}\right)=$ (equipment update rate $\times$ equipment update standard $) \times$ pulse $(0,2)$, units: $\mathrm{RMB} / \mathrm{m}^{2} ;(6)$ Incremental $\operatorname{cost}\left(\mathrm{B}_{1}\right)=\left(\right.$ acquisition cost $\left(\mathrm{L}_{2}\right)+$ usage cost $\left.\left(\mathrm{L}_{1}\right)\right) \times$ pulse $(0,2)$, units: $\mathrm{RMB} / \mathrm{m}^{2}$; (7) Incremental benefit $\left(\mathrm{B}_{2}\right)=\mathrm{IF}$ THENELSE $\left(\right.$ time $<=3,0$, (social benefit $\left(\mathrm{B}_{3}\right)+$ economic benefit $\left(\mathrm{B}_{4}\right)+$ environmental benefit $\left.\left(\mathrm{B}_{5}\right)\right) \times$ pulse $(0,3)$, units: $\mathrm{RMB} / \mathrm{m}^{2}$; (8) Social incremental benefit $\left(\mathrm{B}_{3}\right)=$ (efficiency improvement benefit + disease reduction benefit $) \times$ pulse $(0,3)$, units: yuan $/ \mathrm{m}^{2}$; (9) Economic increment benefit $\left(\mathrm{B}_{4}\right)=$ (government subsidy benefit + energy saving benefit + water saving benefit + material saving benefit + other saving benefit $) \times$ pulse $(0,5)$, units: yuan $/ \mathrm{m}^{2}$; (10) Environmental incremental benefit $\left(\mathrm{B}_{5}\right)=$ (domestic waste treatment benefit + carbon emission reduction benefit $) \times$ pulse $(0,3)$, units: yuan $/ \mathrm{m}^{2}$.

\subsubsection{Model test.}

After the construction of the system model, it is necessary to further test and judge the rationality of the model. By adding or deleting the set variables in the model, we can observe whether the system can still form a closed loop to test the model. First of all, make sure that the variables related to the research problem have been set in the system model. Secondly, check each variable in the estimation model. When one of the variables in the model is eliminated, whether the closed loop can be formed is monitored. When a closed loop cannot be formed due to the elimination of a variable, it means that the variable is endogenous and cannot be deleted. Similarly, this method is used to test other variables in the evaluation model, and the final variables in the model have passed the test, and the model construction is reasonable.

\subsubsection{Empirical analysis.}

This paper selects a residential district which has obtained green building certification in Guangzhou City as an empirical analysis case. The project is 10 residential buildings with a height of 77 meters, and has been awarded two-star green building design logo. A variety of green energy-saving technologies and equipment are used in the internal facilities of the whole residence. Renewable materials and green environmental protection materials are used in the building. The air conditioning system is equipped with automatic air conditioning system, and the fresh air system which can filter and purify the air is installed. In terms of light energy utilization, the external building is installed with point hanging curtain wall solar panels, which can be used to collect solar energy and reduce energy consumption. Each building is equipped with intelligent monitoring sensors, which can detect the working state of air conditioning, water, electric energy and elevator, and timely understand the working state of air quality, water consumption, lighting, etc., and can automatically adjust in case of abnormal conditions.

\subsubsection{Empirical results.}

Through the simulation of its incremental cost and incremental benefits, and the estimated results are studied. Through the analysis of incremental cost and benefit in green building simulation period, the annual incremental cost will be stable by 2025 , with an annual incremental cost of 45 yuan $/ \mathrm{m}^{2}$. The incremental cost in this stage mainly includes the maintenance of new energy-saving equipment and replacement of parts. The incremental benefits of green buildings gradually increase every year, exceed the incremental costs in 2021, and tend to be stable in 2028. The annual incremental benefits of green buildings are 100 yuan $/ \mathrm{m}^{2}$. According to the calculation method of payback period, the incremental cost-benefit balance time point of the residential building project is 8.0 years. 


\section{Conclusions}

Based on the analysis of incremental cost and benefit of green building, the system dynamics model of green building is constructed and tested. Incremental cost includes two stages of incremental cost. Incremental benefit includes economic benefit, social benefit and incremental benefit. The conclusions are as follows:

Firstly, based on the system dynamics model, this paper studies the change law of incremental cost and incremental benefit of green building energy conservation from different perspectives of government, open business and consumer, and confirms that the total incremental benefit of green building is greater than the incremental cost.

Secondly, the two main sources of incremental benefits of green buildings are house appreciation and energy consumption reduction. By analyzing the causal feedback relationship between incremental cost and incremental benefit, and quantitatively studying the external economic benefits of green building projects, the accuracy of the model estimation results is improved.

Thirdly, the benefit of green building to residents is greater than the cost of initial investment. Consumers should have an objective and correct understanding of this. The government should strengthen the publicity and guidance of green buildings, increase subsidies and investment in green buildings, and support and encourage the development of green buildings.

\section{References}

1. Xiaoling Z., A. Platten, and L. Shen, Green property development practice in China: Costs and barriers. Building and Environment, 46(11):p.21532160 (2011)

2. Ai D., Z. Hong, and Y. Wan, Research on the incremental cost-benefit of green buildings from the perspective of consumers. Value Engineering, 038(022):11-15(2019)

3. Eichholtz P., N. Kok , and J. M. Quigley, The Economics of Green Building. Review of Economics and Statistics, 95(1):50-63(2013)

4. Coma J., G.Perez, and A. De Gracia, Vertical greenery systems for energy savings in buildings: A comparative study between green walls and green facades. Building and Environment, 111(JAN.):228237(2017)

5. Yongguang Z., J. Xiaoqing, and Q. ying,System Dynamics (Second Edition). Science Press(2013) 